\title{
Role of Thromboxane in Impaired Renal Vasodilatation Response to Acetylcholine in Hypercholesterolemic Rats
}

\author{
Norman Bank and Hagop S. Aynedjian \\ Renal Division, Department of Medicine, Montefiore Medical Center, and the Albert Einstein College of Medicine, Bronx, New York 10467
}

\begin{abstract}
Short-term cholesterol feeding has been shown to cause impaired vasodilatation in response to acetylcholine. The present study of renal hemodynamics was carried out to examine the role of thromboxane/ $\mathrm{PGH}_{2}$ in mediating this abnormal response. In normal rats (ND), infusion of acetylcholine into the suprarenal aorta caused marked increases in renal blood flow, GFR, single nephron glomerular filtration rate, single nephron afferent plasma flow, and ultrafiltration coefficient, accompanied by a fall in preglomerular resistance. In cholesterol fed rats (CSD), the response to acetylcholine was markedly blunted. Infusion of $\mathrm{L}$-arginine, the precursor to nitric oxide (NO), caused comparable renal vasodilatation in ND and CSD rats, implying that the ability to synthesize NO from its precursor was not severely impaired in the CSD animals. The observations do not exclude, however, the possibility of impaired synthesis of NO from endogenous precursor. In additional experiments, we infused a $\mathrm{TxA}_{2} / \mathbf{P G H}_{2}$ receptor antagonist in CSD rats and then administered acetylcholine. Renal vasodilatation occurred to a degree indistinguishable from that in ND rats given acetylcholine alone. When $N D$ rats were infused with the same combination of the $\mathrm{TxA}_{2} / \mathrm{PGH}_{2}$ receptor antagonist and acetylcholine, renal vasodilatation was also significantly greater than with acetylcholine alone. This suggests that acetylcholine initiates release of vasoconstrictor prostanoids as well as NO from vascular endothelium. This was observed in ND as well as in CSD animals. Because LDL increases the supply of arachidonic acid for prostaglandin synthesis, we postulate that greater amounts of $\mathrm{PGH}_{2} / \mathrm{TxA}_{2}$ are synthesized via calcium activation of phospholipase $A_{2}$ when acetylcholine is administered to CSD animals. This may account in large measure for the blunted vasodilatation to acetylcholine. (J. Clin. Invest. 1992. 89:1636-1642.) Key words: endothelium • prostanoids • EDRF • nitric oxide • micropuncture
\end{abstract}

\section{Introduction}

A considerable body of evidence indicates that short-term experimental hypercholesterolemia $(\mathrm{HC})^{1}$ caused by cholesterol

Received for publication and in revised form.

1. Abbreviations used in this paper: CSD, cholesterol-supplemented diet; EDRF, endothelial-derived relaxing factor; HC, hypercholesterolemia; $K_{\mathrm{f}}$, ultrafiltration coefficient; MAP, mean arterial pressure; ND, normal diet; NO, nitric oxide; $P_{G C}$, glomerular capillary pressure; PLA $_{2}$, phospholipase $A_{2} ; Q_{A}$, single nephron afferent plasma flow; $R_{A}$, preglomerular resistance; $R_{E}$, efferent resistance; $R B F$, renal blood flow; SNBF and SNFF, single nephron blood flow and filtration fraction, respectively.

J. Clin. Invest.

(c) The American Society for Clinical Investigation, Inc.

0021-9738/92/05/1636/07 \$2.00

Volume 89, May 1992, 1636-1642 feeding leads to spontaneous arterial constriction and/or increased responsiveness to various vasoconstrictors (1-13). The vascular beds studied include coronary, cerebral, aorta, hind limb, and renal arteries, and the phenomenon has been demonstrated both in vivo and in isolated vessel preparations studied in vitro. The cholesterol fraction responsible for the increase in vascular reactivity has been shown to be $\operatorname{LDL}(14,15)$, most likely LDL that has been oxidized either in vitro or in vivo (12, 15-20).

The mechanism by which oxidized LDL leads to increased vascular reactivity is not entirely clear, but appears to involve the endothelium, rather than the vascular smooth muscle (VSM). Thus, vasodilators that act directly on VSM, such as sodium nitroprusside, cause a normal degree of dilatation under hypercholesterolemic conditions $(7,13,21,22)$. In contrast, agents that release nitric oxide (NO) from the endothelium, such as acetylcholine, fail to induce normal vasodilatation under similar experimental conditions $(3-6,8,11)$. Several different hypotheses have been proposed to explain these observations. It has been suggested that synthesis or release of $\mathrm{NO}$ is impaired by $\mathrm{HC}(23-25)$. A second conclusion is that NO is synthesized normally or in excess but is metabolized more rapidly before acting on the VSM (22). A third possibility is that $\mathrm{HC}$ increases the production and release of arachidonic acid pathway vasoconstrictors, which counteract the vasodilatory effect of NO.

The present study was undertaken to examine the latter hypothesis. Renal hemodynamic responses to acetylcholine, $\mathrm{L}$-arginine, and a $\mathrm{TxA}_{2} / \mathrm{PGH}_{2}$ receptor antagonist were measured in rats fed a cholesterol supplemented diet (CSD) for 3 wk. The results suggest that the renal endothelium of CSD rats is able to synthesize NO from L-arginine when the latter is provided in excess, and that the VSM relaxes normally to the NO. Although vasodilatation due to acetylcholine was impaired, the response was markedly improved when $\mathrm{TxA}_{2} /$ $\mathrm{PGH}_{2}$ receptors were blocked. We postulate that acetylcholine, by causing a rise in intracellular calcium, activates phospholipase $\mathrm{A}_{2}\left(\mathrm{PLA}_{2}\right)$ and thus prostaglandin synthesis. Because elevations of $L D L$ increase the supply of arachidonic acid, activation of $\mathrm{PLA}_{2}$ could result in greater than normal amounts of $\mathrm{TxA}_{2} / \mathrm{PGH}_{2}$ synthesis and therefore impaired vasodilatation.

\section{Methods}

Male Sprague-Dawley rats weighing 225-275 g were maintained in individual metabolic cages and were fed a daily ration of $25 \mathrm{~g}$ of either a regular normal rat diet (ND) or a pellet supplemented with $4 \%$ cholesterol and 1\% cholic acid (CSD) (Teklad Premier Laboratory Diets, Madison, WI) for $3 \mathrm{wk}$, as previously described (12). The composition of the two diets was exactly the same except for the cholesterol and cholic acid. Each animal consumed the entire $25 \mathrm{~g} / \mathrm{d}$. They had free access to tap water. At the end of the 3-wk period, whole kidney and single nephron hemodynamic studies were carried out. Three groups of animals were studied. 
The surgical preparation of the animals on the day of study and the micropuncture methods have been described previously $(12,26,27)$. General anesthesia was induced by Inactin injection, $100 \mathrm{mg} / \mathrm{kg}$ body wt ip. Catheters were placed in a jugular vein for intravenous infusion, in a carotid artery for monitoring mean arterial pressure (MAP) and obtaining blood samples, and in the abdominal aorta via a femoral artery for infusion of specific agents (see below). The tip of this catheter was positioned $\sim 1 \mathrm{~cm}$ above the left renal artery, by direct visualization. The location of the catheter was confirmed by bolus injection of FD\&C green dye which resulted in a flush of the kidneys. Blood flow to the left kidney was monitored continuously by an ultrasonic flow probe (Transonic Systems, Inc., Ithaca, NY) around the left main renal artery. GFR for both kidneys was measured by $\left[{ }^{14} \mathrm{C}\right]$ inulin clearance via timed urine collections from the urinary bladder. The micropuncture measurements obtained from the left kidney were single nephron glomerular filtration rate (SNGFR), single nephron afferent plasma flow $\left(Q_{A}\right)$, single nephron blood flow (SNBF), glomerular capillary pressure $\left(P_{G C}\right)$, proximal free-flow pressure, transcapillary hydraulic pressure, and single nephron filtration fraction (SNFF). The ultrafiltration coefficient $\left(K_{\mathrm{f}}\right)$ was derived from the mathematical model of Deen et al. (28). Preglomerular resistance $\left(R_{A}\right)$ was calculated as previously described (12).

Group I: acetylcholine infusion. In six ND and six CSD rats, whole kidney and single nephron hemodynamic measurements were made during a control period while isotonic Ringer's solution was infused intravenously at a rate of $1 \mathrm{ml} / \mathrm{h}$ per $100 \mathrm{~g}$ body wt. After these measurements, acetylcholine (Sigma Chemical Co., St. Louis, MO) was infused into the aortic catheter above the two renal arteries at a constant rate of $1 \mu \mathrm{g} / \mathrm{min}$. Repeat whole kidney and single nephron measurements were made during the acetylcholine infusion.

Group II: L-arginine infusion. In six ND and six CSD rats, control whole kidney and single nephron hemodynamic measurements were made, as in the group I animals. After completion of these measurements, L-arginine (Calbiochem-Behring Corp., San Diego, CA) was infused intravenously in a priming dose of $10 \mathrm{mg} / \mathrm{kg}$ followed by a constant infusion at a rate of $10 \mathrm{mg} / \mathrm{kg}$ per min. Repeat whole kidney and single nephron hemodynamic measurements were made during the L-arginine infusion.

Group III: thromboxane receptor antagonist and acetylcholine infusion. In four ND and six CSD rats, the TxA $\mathrm{A}_{2}$ receptor antagonist, $\mathrm{SK} \& \mathrm{~F}$ 96148 (kindly supplied by Smith, Kline \& French Laboratories, Swedeland, PA), was infused into the aorta in a dose of $1 \mathrm{mg} / \mathrm{kg}$, followed by a constant dose of $17 \mu \mathrm{g} / \mathrm{kg}$ per min. Whole kidney and single nephron hemodynamic measurements were made during this infusion. After these measurements were completed, acetylcholine was added to the aortic infusion solution to deliver $1 \mu \mathrm{g} / \mathrm{min}$. Repeat whole kidney and single nephron measurements were made during this combined infusion. In four additional CSD rats, the same experimental protocol was followed except that the angiotensin II receptor antagonist, saralasin, was infused into the aorta $(10 \mu \mathrm{g} / \mathrm{kg}$ bolus followed by $10 \mu \mathrm{g} / \mathrm{kg}$ per min) during period 1. Acetylcholine was then added to this solution during period 2.

Analytical methods. At the end of each experiment, blood was obtained from the aorta for measurement of total cholesterol, triglycerides, and HDL using quantitative enzymatic assays (Sigma Chemical Co.) $(29,30)$. Serum protein was measured by the Lowry method.

Statistical analysis. In each animal, all data from an experimental period were averaged, and this single average was used to calculate the group average \pm SEM. Changes induced by the experimental interventions were calculated by Student's paired $t$ test. Comparisons among the groups were analyzed by ANOVA and tested for significance by the Scheffe post hoc test.

\section{Results}

Measurements of total serum cholesterol in the three groups of experiments are shown in Table I. Rats fed the ND had serum
Table I. Serum Lipids

\begin{tabular}{lllc}
\hline & ND & CSD & $P$ \\
\hline & \multicolumn{3}{c}{$m g / d l$} \\
Total cholesterol & $60.5(10)$ & $360(15)$ & $<0.001$ \\
& \pm 7.2 & \pm 42 & \\
HDL cholesterol & $14.3(10)$ & $28.4(12)$ & $<0.01$ \\
& \pm 1.1 & \pm 4.9 & \\
Triglycerides & $43.1(10)$ & $111(15)$ & $<0.01$ \\
& \pm 3.1 & \pm 15 & \\
& & &
\end{tabular}

Data expressed as means \pm SEM. Numbers in parentheses are the number of animals measured.

cholesterol levels ranging from 40 to $92 \mathrm{mg} / \mathrm{dl}$. Those fed the CSD had serum cholesterol levels five to eight times higher, ranging from 250 to $590 \mathrm{mg} / \mathrm{dl}$ in individual animals. Fractionation of serum cholesterol, carried out in a previous study (12), showed that the CSD caused marked increases in VLDL and LDL, but relatively small effects on HDL and fasting triglyceride levels.

Group I: acetylcholine infusion. The renal hemodynamic responses to infusion of acetylcholine into the suprarenal aorta are shown in Table II. MAP was within the normal range in both the ND and CSD rats. Infusion of acetylcholine into the aorta resulted in a 4-mmHg decrease in MAP in the ND rats $(P$ $<0.05$ ) but no significant change in the CSD animals. As can be seen in Table II, during the control period (period 1), whole kidney and single nephron blood flow and filtration rate were significantly lower in the CSD rats than in the ND rats. In addition, $\mathrm{Q}_{\mathrm{A}}$ and $K_{\mathrm{f}}$ were lower and $\mathrm{SNFF}$ and $\mathrm{P}_{\mathrm{GC}}$ were higher in the CSD rats. These findings are closely comparable to data previously reported by our laboratory on the effect of CSD on renal hemodynamics (12). With infusion of acetylcholine (period 2), a marked rise in renal blood flow (RBF), GFR, SNGFR, $Q_{A}, S N B F$, and $K_{f}$ occurred in the ND rats, and $R_{A}$ fell. There was no significant effect on either $P_{G C}$ or SNFF. In the CSD animals, acetylcholine also caused significant changes in the same hemodynamic parameters, but the magnitude of response was much smaller. Moreover, all of the flow values during period 2 in the CSD rats remained significantly below the period 2 values in the ND rats, and $\mathrm{R}_{\mathrm{A}}$ remained higher $(P$ $<0.05$ ).

Percent increases in SNGFR and $Q_{A}$ and decreases in $R_{A}$ due to acetylcholine are illustrated in Fig. 1. In the ND rats, SNGFR and $Q_{A}$ rose by $24-27 \%$. In sharp contrast, in the CSD rats, acetylcholine induced a rise of only $10-15 \%$. The percent decrease in $\mathbf{R}_{\mathbf{A}}$ was also markedly blunted in the CSD animals.

Group II: L-arginine infusion. Table III presents the renal hemodynamic data for the experiments in which L-arginine was infused during period 2 . There were no significant effects of L-arginine infusion on MAP. As can be seen in the table, in the ND rats L-arginine caused marked increases in RBF, GFR, SNGFR, $Q_{A}, S N B F$, and $K_{f}$, but did not alter SNFF or $P_{G C} \cdot R_{A}$ fell significantly. In the CSD rats, the L-arginine infusion caused quantitatively similar changes in all of these hemodynamic parameters and, in addition, a significant fall in SNFF. The absolute values for GFR, SNFF, $S N B F$, and $R_{A}$ were statistically equal to those in the ND rats, but those for $R B F$, $\mathrm{SNGFR}, \mathrm{P}_{\mathrm{GC}}$ and $K_{\mathrm{f}}$ remained significantly different. The per- 
Table II. Effect of Acetylcholine on Renal Hemodynamics (Period 2)

\begin{tabular}{|c|c|c|c|c|c|c|c|c|c|c|c|}
\hline Group & Period & MAP & RBF & GFR & SNGFR & $\mathrm{Q}_{A}$ & SNBF & SNFF & $\mathbf{P}_{\mathrm{GC}}$ & $\mathbf{R}_{\mathbf{A}} \times 10^{10}$ & $K_{\mathrm{f}}$ \\
\hline & & $\mathrm{mmHg}$ & & & & $\mathrm{nl} / \mathrm{min}$ & & & $m m H g$ & dyn $\cdot s \cdot \mathrm{cm}^{-s}$ & $\begin{array}{c}\text { nl/min } \\
\text { per } m m H g\end{array}$ \\
\hline \multirow[t]{2}{*}{$\mathrm{ND}(6)$} & 1 & $120 \pm 2.8$ & $6.51 \pm 0.06$ & $2.11 \pm 0.09$ & $29.5 \pm 0.4$ & $93.2 \pm 4.0$ & $174 \pm 8$ & $0.32 \pm 0.01$ & $49.1 \pm 0.4$ & $3.25 \pm 0.22$ & $2.15 \pm 0.11$ \\
\hline & 2 & $116 \pm 1.9$ & $7.82 \pm 0.06$ & $3.77 \pm 0.26$ & $36.6 \pm 0.6$ & $117.5 \pm 4.9$ & $216 \pm 8$ & $0.31 \pm 0.01$ & $49.3 \pm 0.5$ & $2.46 \pm 0.13$ & $2.56 \pm 0.08$ \\
\hline$P$ (paired $t$ test) & & $<0.05$ & $<0.001$ & $<0.05$ & $<0.001$ & $<0.01$ & $<0.01$ & NS & NS & $<0.01$ & $<0.01$ \\
\hline \multirow[t]{2}{*}{$\operatorname{CSD}(6)$} & 1 & $115 \pm 1.3$ & $5.46 \pm 0.04$ & $1.56 \pm 0.04$ & $25.4 \pm 0.7$ & $71.9 \pm 2.7$ & $137 \pm 5$ & $0.35 \pm 0.01$ & $52.0 \pm 0.4$ & $3.67 \pm 0.14$ & $1.50 \pm 0.03$ \\
\hline & 2 & $113 \pm 0.8$ & $5.64 \pm 0.04$ & $1.63 \pm 0.05$ & $27.8 \pm 0.6$ & $82.9 \pm 1.6$ & $156 \pm 4$ & $0.34 \pm 0.01$ & $51.9 \pm 0.4$ & $3.12 \pm 0.08$ & $1.66 \pm 0.09$ \\
\hline$P$ (paired $t$ test) & & NS & $<0.001$ & $<0.05$ & $<0.05$ & $<0.05$ & $<0.05$ & NS & NS & $<0.05$ & NS \\
\hline
\end{tabular}

ANOVA: ND vs. CSD: period 1: all data $<0.05$ except $R_{A}$, period 2: all data $<0.05$ except SNFF.

cent changes for some of the hemodynamic parameters that occurred with L-arginine infusion are shown in Fig. 2. As is shown, changes in SNGFR and $R_{A}$ were similar in ND and CSD animals, whereas the rise in $Q_{A}$ was actually greater in the CSD rats than in the ND rats.

Group III: TXA $\mathrm{A}_{2}$ receptor antagonist-acetylcholine infusion. In Table IV are shown the renal hemodynamic responses to acetylcholine in ND and CSD rats infused with the $\mathrm{TxA}_{2} /$ $\mathrm{PGH}_{2}$ receptor antagonist SK\&F 96148 before acetylcholine administration. During period 1, all of the renal hemodynamic measurements were statistically the same in these two groups of animals. Thus, the $\mathrm{TxA}_{2}$ receptor antagonist had presumably restored to normal the hemodynamic values of the CSD animals. This is in agreement with previously published findings from our laboratory (12). During period 2, when acetylcholine was added to the $\mathrm{TxA}_{2} / \mathrm{PGH}_{2}$ antagonist infusion, significant increases in RBF, GFR, SNGFR, $Q_{A}$, and SNBF occurred in both groups, and $R_{A}$ fell significantly. The percent changes in SNGFR, $Q_{A}$, and $R_{A}$ for CSD rats infused with acetylcholine $\pm \mathrm{TxA} \mathrm{A}_{2} / \mathrm{PGH}_{2}$ antagonist are shown in Fig. 3. It is evident that the presence of the receptor antagonist markedly increased the response to acetylcholine in these animals. The receptor antagonist appeared to also enhance the response to acetylcholine in the ND rats. This is shown in Table V, where the data for period 2 from Tables II and IV are compared statistically. It can

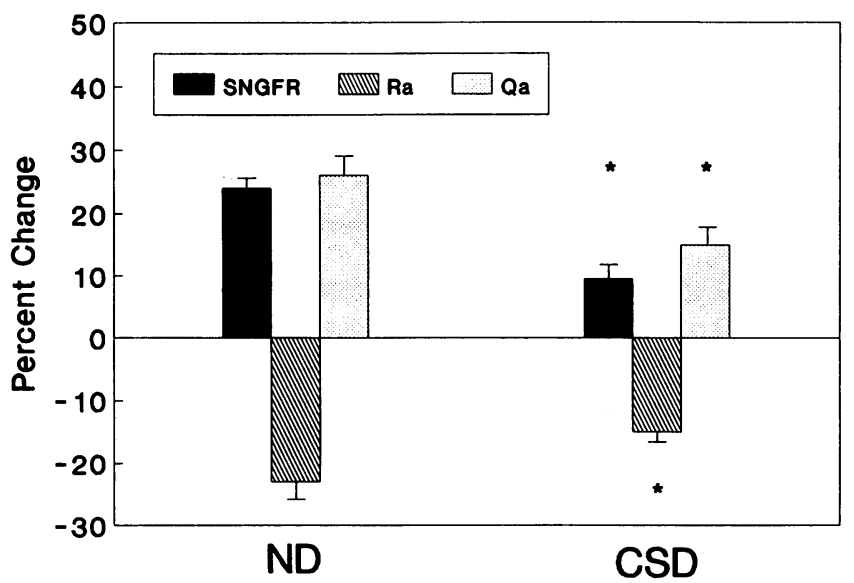

Figure 1. Effects of intraaortic acetylcholine infusion on SNGFR, $\mathrm{Q}_{\mathrm{A}}$, and $\mathrm{R}_{\mathrm{A}} \cdot N D$, normal diet. $C S D$, cholesterol-supplemented diet. Data presented as percent change from period 1 control values. Asterisk indicates $P<0.05$ CSD vs. ND. be seen that almost all hemodynamic measurements were significantly different in ND rats given the combination of drugs versus acetylcholine alone. Thus, blockade of $\mathrm{TxA}_{2} / \mathrm{PGH}_{2}$ receptors enhanced the vasodilatory effect of acetylcholine in ND rats as well as in CSD rats.

Because of these findings, we have compared the absolute hemodynamic values in CSD vs ND rats under the same experimental conditions of $\mathrm{TxA}_{2} / \mathrm{PGH}_{2}$ blockade + acetylcholine. These data are shown in Table VI. It is evident that the combination of drugs resulted in significantly higher values for SNGFR, $Q_{A}$, and SNBF and lower values for SNFF and $R_{A}$ in the ND than in the CSD rats.

In four additional rats fed the CSD for 3-wk, saralasin was infused into the aorta during the first period and saralasin + acetylcholine during the second period. The hemodynamic values during the coinfusion of saralasin + acetylcholine are also shown in Table VI. It can be seen that angiotensin II blockade with saralasin did not improve the renal hemodynamic response to acetylcholine as much as did $\mathrm{TxA}_{2} / \mathrm{PGH}_{2}$ receptor blockade. However, some small effect of saralasin was evident, since $\mathrm{SNGFR}, \mathrm{Q}_{\mathrm{A}}, \mathrm{SNBF}, \mathrm{R}_{\mathrm{A}}$, and $K_{\mathrm{f}}$ are significantly different from the values measured in CSD rats given acetylcholine alone (Table II).

\section{Discussion}

Short-term $\mathrm{HC}$ has been found to increase vascular tone and the reactivity to vasoconstrictors in a number of vascular beds (1-13), including the renal blood vessels (12). In vitro studies indicate that oxidized LDL and, to a lesser extent, VLDL are responsible for the abnormalities $(14,15)$. Because the abnormal reactivity occurs after a relatively brief exposure of blood vessels to cholesterol, when endothelial pathology or fatty streaks have not yet developed, the impaired response is thought to be due to functional rather than structural changes. The most characteristic abnormality described in several different vascular beds is a blunted vasodilatory response to acetylcholine $(3-6,8,11)$.

The present experiments demonstrate that the renal blood vessels in CSD rats also have a blunted response to acetylcholine. As shown in Table II and Fig. 1, infusion of acetylcholine into the aorta of $\mathrm{HC}$ rats resulted in only relatively small increases in RBF and GFR compared with rats on a ND. In the ND rats, single nephron hemodynamic measurements demonstrated increases in $\mathrm{SNBF}$ and $\mathrm{Q}_{\mathrm{A}}$, which were due to a significant fall in $\mathrm{R}_{\mathrm{A}}$. In addition, there was no change in SNFF or 
Table III. Effect of L-Arginine on Renal Hemodynamics (Period 2)

\begin{tabular}{|c|c|c|c|c|c|c|c|c|c|c|c|}
\hline Group & Period & MAP & RBF & GFR & SNGFR & $Q_{A}$ & SNBF & SNFF & $P_{G C}$ & $\mathbf{R}_{\mathbf{A}} \times 10^{10}$ & $K_{\mathrm{f}}$ \\
\hline & & $m m H g$ & $\mathrm{ml} /$ & $\min$ & & $n l / m i n$ & & & $m m H g$ & $d y n \cdot s \cdot \mathrm{cm}^{-s}$ & $\begin{array}{c}n l / m i n \\
\text { per } m m H g\end{array}$ \\
\hline \multirow[t]{2}{*}{ ND (6) } & 1 & $121 \pm 1.0$ & $6.24 \pm 0.08$ & $1.98 \pm 0.04$ & $31.4 \pm 0.6$ & $101 \pm 3$ & $187 \pm 7$ & $0.31 \pm 0.01$ & $47.8 \pm 0.3$ & $3.07 \pm 0.13$ & $2.14 \pm 0.10$ \\
\hline & 2 & $117 \pm 0.25$ & $7.06 \pm 0.11$ & $2.42 \pm 0.07$ & $39.6 \pm 1.3$ & $133.7 \pm 3.7$ & $245 \pm 8$ & $0.30 \pm 0.01$ & $48.3 \pm 0.4$ & $2.26 \pm 0.08$ & $2.59 \pm 0.12$ \\
\hline$P$ (paired $t$ test) & & NS & $<0.01$ & $<0.001$ & $<0.001$ & $<0.05$ & $<0.01$ & NS & NS & $<0.01$ & $<0.01$ \\
\hline \multirow[t]{2}{*}{$\operatorname{CSD}(6)$} & 1 & $116 \pm 1.0$ & $5.37 \pm 0.11$ & $1.82 \pm 0.06$ & $26.8 \pm 0.5$ & $75.3 \pm 1.6$ & $140 \pm 4$ & $0.36 \pm 0.01$ & $52.0 \pm 0.4$ & $3.53 \pm 0.05$ & $1.67 \pm 0.08$ \\
\hline & 2 & $115 \pm 3.2$ & $6.08 \pm 0.1$ & $2.14 \pm 0.08$ & $34.3 \pm 0.7$ & $117 \pm 6$ & $217 \pm 13$ & $0.30 \pm 0.01$ & $51.3 \pm 0.6$ & $2.32 \pm 0.17$ & $1.92 \pm 0.07$ \\
\hline$P$ (paired $t$ test) & & NS & $<0.01$ & $<0.01$ & $<0.01$ & $<0.01$ & $<0.01$ & $<0.01$ & NS & $<0.01$ & $<0.01$ \\
\hline
\end{tabular}

ANOVA: ND vs. CSD: period 1: all comparisons $<0.05$ except GFR and $\mathrm{R}_{\mathrm{A}}$; period 2: RBF, SNGFR, $\mathrm{P}_{\mathrm{GC}}$, and $K_{\mathrm{f}}<0.05 ; \mathrm{GFR}, \mathrm{SNFF}, \mathrm{Q}_{\mathrm{A}}$, SNBF, and $R_{A}$, NS.

$P_{G C}$, making it likely that efferent resistance $\left(R_{E}\right)$ also decreased. Thus, the effect of acetylcholine was to cause renal VSM relaxation at both pre- and postglomerular sites. There was, in addition, a significant increase in $K_{\mathrm{f}}$, a change that contributed to the rise in filtration rate. This latter observation suggests, therefore, that NO released from nearby endothelial cells may have acted on glomerular mesangial cells as well, or that acetylcholine directly stimulated synthesis of NO by the mesangial cells.

In the $\mathrm{HC}$ rats, blood flow and filtration rates were significantly lower than in the ND animals during the control period, findings in agreement with a previously published study by our laboratory (12). When acetylcholine was infused into the aorta of these animals (Table II), a significant vascular relaxation at pre- and postglomerular sites occurred, but the response was much less than in the ND rats (Table II and Fig. 1).

To determine whether this blunted response to acetylcholine was due to a limited capacity of the renal endothelium to synthesize or release NO, we infused L-arginine, the normal endogenous precursor of NO synthesis. The results, shown in Table III and Fig. 2, indicate that in the ND rats, renal blood vessels dilate markedly in response to L-arginine. RBF, GFR, $\mathrm{SNBF}$, and $\mathrm{Q}_{\mathrm{A}}$ increased strikingly, as did SNGFR. This was accompanied by a fall in $R_{A}$ but no significant change in $P_{G C}$ or SNFF. This combination of findings suggests that $R_{E}$ fell in proportion to the fall in $\mathrm{R}_{\mathrm{A}} . K_{\mathrm{f}}$ rose, which contributed to the increase in filtration rate. Thus, the renal vascular responses to

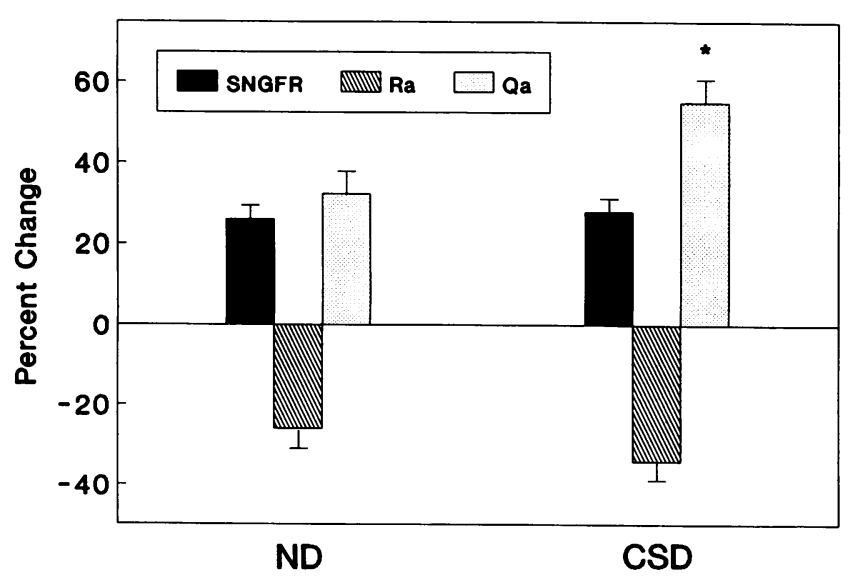

Figure 2. Effects of L-arginine infusion on renal hemodynamics. Labels same as in Fig. 1. infusion of L-arginine in the ND rats were qualitatively similar to those induced by acetylcholine.

In the $\mathrm{HC}$ rats, $\mathrm{L}$-arginine infusion resulted in a degree of renal vasodilatation that was quantitatively comparable to that in the ND rats (Table III). GFR, SNBF, $Q_{A}$, and $R_{A}$ all reached values that were not significantly different from those in the ND rats. As shown in Fig. 2, the percent changes in SNGFR, $Q_{A}$, and $R_{A}$ with $L$-arginine infusion were as great if not greater than in the ND rats. These findings could be interpreted to mean that there is a deficiency of endogenous L-arginine in $\mathrm{HC}$ rats. Alternatively, the findings are consistent with impaired enzymatic synthesis of NO from endogenous L-arginine, but this can be overcome by administration of a large amount of $\mathrm{L}$-arginine. Several other investigators have examined the effect of $\mathrm{L}$-arginine administration on the impaired vasodilatation of blood vessels removed from HC animals. Cooke et al. (23) infused $\mathrm{L}$-arginine into $\mathrm{HC}$ rabbits for $70 \mathrm{~min}$ and then studied their excised thoracic aortic rings in vitro. They found that the L-arginine infusion (but not D-arginine) normalized the in vitro relaxation response of the rings to acetylcholine. Infusion of L-arginine in normal rabbits had no effect on the relaxation response of their aortic rings. The same laboratory demonstrated that cerebral basilar arteries from HC rabbits manifested impaired relaxation in response to acetylcholine and that in vitro exposure of the arteries to L-arginine normalized the acetylcholine response (24). In an in vivo study of femoral artery blood flow in $\mathrm{HC}$ rabbits, these investigators found that L-arginine augmented the vasodilatation response to acetylcholine (25). They suggested that HC may induce a reversible reduction in intracellular arginine availability or metabolism, which was corrected by exogenous L-arginine. Our observations are in accord with their results. However, Minor et al. (22) directly measured the in vitro release of NO from the aortas of $\mathrm{HC}$ rabbits by chemiluminescence and found it to be markedly increased. Addition of acetylcholine caused a further increase in NO release. In spite of this, they found, in a bioassay organ chamber, that the NO released by aortas from $\mathrm{HC}$ rabbits failed to cause relaxation of downstream normal detector vessels. They concluded, therefore, that HC does not impair NO synthesis, but it may cause loss of incorporation of NO into another vasoactive compound, or it accelerates the rate of degradation of endothelial-derived relaxing factor (EDRF). Thus, a specific abnormality in EDRF metabolism has not yet been identified in $\mathrm{HC}$ animals.

Because it is well established that HC increases thromboxane production and aggregation of platelets (31-33) and in- 
Table IV. Effect of TxA $A_{2}$ Blockade on Acetylcholine-induced Vasodilatation

\begin{tabular}{|c|c|c|c|c|c|c|c|c|c|c|c|}
\hline Group & Period & MAP & $\mathbf{R B F}$ & GFR & SNGFR & QA & SNBF & SNFF & $\mathbf{P}_{\mathrm{OC}}$ & $\mathbf{R}_{\mathbf{A}}$ & $K_{f}$ \\
\hline & & $\mathrm{mmHg}$ & $\mathrm{ml} /$ & $\min$ & & $n l / \min$ & & & $\mathrm{mmHg}$ & $d y n \cdot s \cdot \mathrm{cm}^{-5} \times 10^{10}$ & $\begin{array}{c}n l / m i n \\
\text { per } m m H g\end{array}$ \\
\hline \multirow[t]{4}{*}{ ND (4) } & 1 & \multicolumn{10}{|c|}{ Infusion of $\mathrm{TxA}_{2}$ receptor antagonist into aorta } \\
\hline & & $114 \pm 2.0$ & $6.14 \pm 0.07$ & $2.01 \pm 0.03$ & $30.4 \pm 0.6$ & $94.1 \pm 2.7$ & $175 \pm 5.9$ & $0.33 \pm 0.01$ & $48.6 \pm 0.5$ & $3.12 \pm 0.20$ & $2.08 \pm 0.13$ \\
\hline & 2 & \multicolumn{10}{|c|}{ Infusion of $\mathrm{TxA}_{2}$ receptor antagonist + acetylcholine into aorta } \\
\hline & & $115 \pm 1.8$ & $7.95 \pm 0.19$ & $2.45 \pm 0.05$ & $39.8 \pm 0.8$ & $146 \pm 5.5$ & $269 \pm 10$ & $0.27 \pm 0.01$ & $49.1 \pm 0.6$ & $1.95 \pm 0.05$ & $2.47 \pm 0.06$ \\
\hline$P$ (paired $t$ test) & & NS & $<0.001$ & $<0.001$ & $<0.01$ & $<0.01$ & $<0.01$ & $<0.01$ & NS & $<0.01$ & $<0.05$ \\
\hline \multirow[t]{4}{*}{$\operatorname{CSD}(6)$} & 1 & \multicolumn{10}{|c|}{ Infusion of $\mathrm{TxA}_{2}$ receptor antagonist into aorta } \\
\hline & & $116 \pm 1.4$ & $5.41 \pm 0.09$ & $1.92 \pm 0.05$ & $28.3 \pm 0.3$ & $84.6 \pm 1.7$ & $161 \pm 3.2$ & $0.34 \pm 0.01$ & $50.1 \pm 0.3$ & $3.28 \pm 0.06$ & $2.06 \pm 0.08$ \\
\hline & 2 & \multicolumn{10}{|c|}{ Infusion of $\mathrm{TxA}_{2}$ receptor antagonist + acetylcholine into aorta } \\
\hline & & $115 \pm 2.2$ & $5.97 \pm 0.04$ & $2.09 \pm 0.05$ & $35.2 \pm 0.3$ & $111.6 \pm 2.1$ & $206 \pm 3.6$ & $0.32 \pm 0.01$ & $49.6 \pm 0.3$ & $2.53 \pm 0.05$ & $2.27 \pm 0.08$ \\
\hline$P$ (paired $t$ test) & & NS & $<0.01$ & $<0.001$ & $<0.001$ & $<0.001$ & $<0.001$ & $<0.05$ & NS & $<0.001$ & NS \\
\hline
\end{tabular}

ANOVA: period 2 data for ND not significantly different from period 2 with acetylcholine alone (Table II), period 2 data for CSD all significantly different from period 2 for CSD rats given acetylcholine alone (Table II).

creases urinary excretion of $\mathrm{TxB}_{2}(12)$, we examined the role of $\mathrm{TxA}_{2}$ in the impaired vasodilator response to acetylcholine. These experiments, shown in Table IV and Fig. 3, demonstrated that infusion of a $\mathrm{TxA}_{2} / \mathrm{PGH}_{2}$ receptor antagonist markedly increased the vasodilatory effect of acetylcholine in HC rats. GFR, SNGFR, $Q_{A}, S N B F$, and $K_{\mathrm{f}}$ all rose to levels indistinguishable from those in the ND rats infused with acetylcholine alone. Thus, blockade of $\mathrm{TxA}_{2} / \mathrm{PGH}_{2}$ receptors appeared to specifically restore the responsiveness to acetylcholine in the $\mathrm{HC}$ rats. We conclude from these observations that $\mathrm{TxA}_{2}$ and/or a precursor constrictor endoperoxide $\left(\mathrm{PGH}_{2}\right)$ is largely responsible for the blunted renal dilatation to acetylcholine in the $\mathrm{HC}$ rats. However, experiments in other vascular beds have yielded conflicting results with regard to the role of endothelial prostanoids in HC vasoactive abnormalities. For example, in studies of human coronary arteries from patients undergoing bypass surgery, Fostermann et al. (13) found impaired relaxation to several EDRF-releasing agents, but inhibition of cyclooxygenase with indomethacin did not enhance the relaxation response. In an in vitro bioassay study of isolated

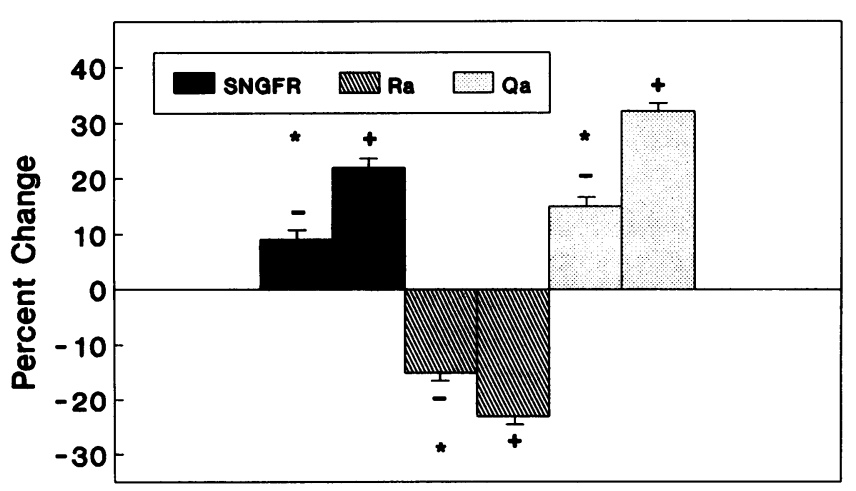

\section{CSD}

Figure 3. Effects of acetylcholine with and without $\mathrm{TxA}_{2} / \mathrm{PGH}_{2} \mathrm{re}-$ ceptor antagonist on $S N G F R, Q_{A}$, and $R_{A}$. coronary arteries from cholesterol-fed pigs, Minor et al. (22) found impaired relaxation of downstream detector vessels after administration of acetylcholine to arteries from $\mathrm{HC}$ animals in spite of the presence of indomethacin. Simon et al. (15) studied the effect of oxidized LDL on coronary arteries from normal pigs. They found that addition of oxidized LDL caused contraction of these vessels, but this was not prevented by indomethacin. However, in these experiments the thromboxane mimetic drug U46619 was used routinely to preconstrict the blood vessels, and therefore inhibition of endogenous $\mathrm{TxA}_{2}$ by indomethacin might not have had a detectable effect.

In contrast to these studies, it has been found that endothelial-produced $\mathrm{TxA}_{2} / \mathrm{PGH}_{2}$ can interfere with the relaxation response to acetylcholine in two different experimental models, i.e., vessels from SHR rats and vessels exposed to high glucose concentrations. Luscher and Vanhoutte (34) found that aortic rings from SHR rats failed to dilate normally in response to acetylcholine and that this was normalized by cyclooxygenase inhibition, but not thromboxane synthetase or leukotriene synthetase inhibition. They concluded that the impaired relaxation was due to release of an endothelial contracting factor

Table V. Comparison of Hemodynamic Data in ND Rats Infused with Either Acetylcholine Alone or TxA Receptor Antagonist + Acetylcholine

\begin{tabular}{lccc}
\hline & Ach & $\begin{array}{c}\text { TxA } \\
\text { antagonist + Ach }\end{array}$ & $P$ \\
\hline SNGFR $(\mathrm{nl} / \mathrm{min})$ & $36.6 \pm 0.6$ & $39.8 \pm 0.8$ & $<0.01$ \\
$\mathrm{Q}_{\mathrm{A}}(\mathrm{nl} / \mathrm{min})$ & $117.5 \pm 4.9$ & $146 \pm 5.5$ & $<0.01$ \\
$\mathrm{SNBF}(\mathrm{nl} / \mathrm{min})$ & $216 \pm 8$ & $269 \pm 10$ & $<0.01$ \\
$\mathrm{SNFF}$ & $0.31 \pm 0.01$ & $0.27 \pm 0.01$ & $<0.05$ \\
$\mathrm{P}_{\mathrm{GC}}(\mathrm{mmHg})$ & $49.3 \pm 0.5$ & $49.1 \pm 0.6$ & $\mathrm{NS}$ \\
$\mathrm{R}_{\mathrm{A}}\left(10^{\prime 0} \mathrm{dyn} \cdot \mathrm{s} \cdot \mathrm{cm}^{-5}\right)$ & $2.46 \pm 0.13$ & $1.95 \pm 0.05$ & $<0.02$ \\
$K_{\mathrm{f}}(\mathrm{nl} / \mathrm{min} \mathrm{per} \mathrm{mmHg})$ & $2.56 \pm 0.08$ & $2.47 \pm 0.06$ & $\mathrm{NS}$ \\
& & &
\end{tabular}

Data from period 2 of Tables II and IV. Statistical analysis by ANOVA and Scheffe test for groups with significant differences. Ach, acetylcholine. 
Table VI. Comparison of Hemodynamic Data in Rats Infused with TxA $A_{2}$ Receptor Antagonist + Acetylcholine or Saralasin + Acetylcholine

\begin{tabular}{lccccc}
\hline & $\mathrm{ND}$ & & $\mathrm{CSD}$ & & $\mathrm{CSD}$ \\
\cline { 2 - 3 } & $\begin{array}{c}\mathrm{TxA}_{2} \\
\text { Antagonist + Ach }\end{array}$ & $\begin{array}{c}\mathrm{TxA}_{2} \\
\text { Antagonist + Ach }\end{array}$ & $\begin{array}{c}\text { Saralasin } \\
+ \text { Ach }\end{array}$ \\
\hline SNGFR $(\mathrm{nl} / \mathrm{min})$ & $39.8 \pm 0.8$ & & $35.2 \pm 0.3^{\ddagger}$ & & $31.1 \pm 0.4^{*}$ \\
$\mathrm{Q}_{\mathrm{A}}(\mathrm{nl} / \mathrm{min})$ & $146 \pm 5.5$ & & $111.6 \pm 2.1^{\dagger}$ & & $91 \pm 2.2^{*}$ \\
$\mathrm{SNBF}(\mathrm{nl} / \mathrm{min})$ & $269 \pm 10$ & & $206 \pm 3.6^{\dagger}$ & & $171 \pm 4.5^{*}$ \\
$\mathrm{SNFF}$ & $0.27 \pm 0.01$ & & $0.32 \pm 0.01^{\dagger}$ & & $0.34 \pm 0.01$ \\
$\mathrm{P}_{\mathrm{GC}}(\mathrm{mmHg})$ & $49.1 \pm 0.6$ & & $49.6 \pm 0.3$ & & $52.7 \pm 1.1^{*}$ \\
$\mathrm{R}_{\mathrm{A}}\left(10^{10} \mathrm{dyn} \cdot \mathrm{s} \cdot \mathrm{cm}^{-5}\right)$ & $1.95 \pm 0.05$ & & $2.53 \pm 0.05^{\dagger}$ & $2.68 \pm 0.15$ \\
$K_{\mathrm{f}}(\mathrm{nl} / \mathrm{min} \mathrm{per} \mathrm{mmHg})$ & $2.47 \pm 0.06$ & & $2.27 \pm 0.08$ & & $2.13 \pm 0.07$ \\
\hline
\end{tabular}

Data for CSD taken from Table IV, period 2. Analysis by ANOVA and Scheffé test for groups with significant differences. ${ }^{*} P<0.05$ $\operatorname{CSD}\left(\mathrm{TxA}_{2}\right.$ receptor antagonist) vs. CSD (saralasin); ${ }^{\dagger} P<0.02 \mathrm{ND}$ vs. $\mathrm{CSD}\left(\mathrm{TxA}_{2}\right.$ receptor antagonist). Ach, acetylcholine.

which is a cyclooxygenase product. Tesfamariam et al. (35) studied isolated normal rabbit aortas exposed to high concentrations of glucose. High glucose was found to impair acetylcholine-induced relaxation. The high glucose concentrations increased the release of $\mathrm{TxB}_{2}$ and $\mathrm{PGF}_{2 \alpha}$ when acetylcholine was applied. Prior inhibition of cyclooxygenase, or administration of a $\mathrm{TxA}_{2}$ receptor antagonist (SQ 29548), restored the acetylcholine-induced relaxation to normal (35). Thus, vasoconstrictor prostanoids produced by the endothelium accounted for impaired NO-induced relaxation under these two experimental conditions. Our observations suggest that this is also the case in experimental HC. It should be noted that the receptor antagonist used in these studies does not distinguish between $\mathrm{TxA}_{2}$ and $\mathrm{PGH}_{2}$. However, on the basis of studies of others, in which a $\mathrm{TxA}_{2}$ synthetase inhibitor did not block the effects of constrictor prostanoids $(34,36)$, whereas a receptor antagonist did $(35,36)$, it seems likely that the endoperoxide $\mathrm{PGH}_{2}$ was the cause of the impaired vasodilator response, rather than $\mathrm{TxA}_{2}$ per se.

It has been shown by Tesfamariam et al. (35) that the aortic endothelium of normal rabbits synthesizes $\mathrm{TxA}_{2}, \mathrm{PGF}_{2 \alpha}$, 6keto-PGF $1 \alpha$, and $\mathrm{PGE}_{2}$ under basal in vitro conditions. When acetylcholine was added, the release of all these compounds increased markedly. Thus, acetylcholine has a complex effect on the vascular endothelium, causing release not only of NO, but constricting and dilating prostaglandins as well. The interaction of acetylcholine with its receptors on the surface of endothelial cells leads to a rise in intracellular calcium by voltagedependent and receptor-operated calcium channels. The rise in cell calcium is thought to activate NO synthase, resulting in increased NO production. Calcium also activates $\mathrm{PLA}_{2}$, which increases the supply of arachidonic acid for prostaglandin synthesis. Thus, administration of acetylcholine most likely activates both enzymes, accounting for the observed release of both $\mathrm{NO}$ and prostanoids from isolated vessels (35). In our experiments in ND rats, we observed that blockade of $\mathrm{TxA}_{2} /$ $\mathrm{PGH}_{2}$ receptors enhanced the vasodilatory response to acetylcholine (Table V). We conclude, therefore, that acetylcholine administration evokes release of vasoconstrictor prostanoids as well as NO, and the hemodynamic response is the net effect of these opposing vasoactive substances.
Because elevated levels of LDL enrich cell membranes with cholesterol and arachidonic acid (37), activation of PLA $\mathrm{P}_{2}$ in endothelial cells would be expected to generate larger than normal amounts of prostaglandins. We propose that this accounts in large part for the impaired vasodilatory response to acetylcholine observed in the cholesterol-fed rats.

Blockade of AII receptors with saralasin did not restore responsiveness to acetylcholine, as did blockade of $\mathrm{TxA}_{2}$ receptors (Table VI). However, saralasin did improve renal hemodynamics slightly in the CSD rats, suggesting a minor role for AII in the hemodynamic abnormalities of the CSD animals.

Although TxA $/ \mathrm{PGH}_{2}$ blockade improved the renal vasodilatory response to acetylcholine in the CSD rats, the absolute levels of single nephron flow rates did not reach those in the ND rats infused with the same combination of $\mathrm{TxA}_{2}$ antagonist + acetylcholine. The data for these two groups are compared statistically in Table VI. It is evident that most values were significantly different in the CSD rats versus the ND rats. It appears, therefore, that an additional abnormality existed in the CSD animals, not completely corrected by blocking $\mathrm{TxA}_{2}$ / $\mathrm{PGH}_{2}$ receptors. The nature of this additional factor is not clear, but it could be a defect in NO metabolism or an abnormality in other vasodilator or vasoconstrictor chemicals.

The clinical implications of these findings with regard to renal disease is uncertain. Long-term $\mathrm{HC}$ has been shown to exacerbate renal injury in several different models of renal disease $(38,39)$. The mechanism is unknown, but may involve activation of growth factors and prostanoids, as well as causing hemodynamic changes (39). Thromboxane has been shown to have direct effects on glomerular mesangial cells (40) and the synthesis of extracellular matrix (41). It seems possible, therefore, that the increased thromboxane synthesis induced by HC contributes to accelerated glomerular injury found when HC coexists with intrinsic renal disease.

\section{Acknowledgments}

This study was supported by U. S. Public Health Service grant 5 ROI DK-32469.

\section{References}

1. Shimokawa, H., H. Tomoike, S. Nabeyama, H. Yamamoto, H. Araki, and M. Nakamura. 1983. Coronary artery spasm induced in atherosclerotic miniature swine. Science (Wash. DC). 221:560-562.

2. Heistad, D. D., M. L. Armstrong, M. L. Marcus, D. J. Piegors, and A. L. Mark. 1984. Augmented responses to vasoconstrictor stimuli in hypercholesterolemic and atherosclerotic monkeys. Circ. Res. 54:711-718.

3. Jayakody, R. L., M. P. J. Senaratne, A. B. R. Thomson, and C. T. Kappagoda. 1985. Cholesterol feeding impairs endothelium-dependent relaxation of rabbit aorta. Can. J. Physiol. Pharmacol. 63:1206-1209.

4. Freiman, P. C., G. G. Mitchell, D. D. Heistad, M. L. Armstrong, and D. G. Harrison. 1986. Atherosclerosis impairs endothelium-dependent vascular relaxation to acetylcholine and thrombin in primates. Circ. Res. 58:783-789.

5. Sreeharan, N., R. L. Jayakody, M. P. J. Senaratne, A. B. R. Thomson, and C. T. Kappakoda. 1986. Endothelium-dependent relaxation and experimental atherosclerosis in the rabbit aorta. Can. J. Physiol. Pharmacol. 64:1451-1453.

6. Chappel, S. P., M. J. Lewis, and A. H. Henderson. 1987. Effect of lipid feeding on endothelium dependent relaxation in rabbit aortic preparations. $\mathrm{Car}$ diovasc. Res. 21:34-38.

7. Harrison, D. G., P. C. Freiman, M. L. Armstrong, M. L. Marcus, and D. D. Heistad. 1987. Alterations of vascular reactivity in atherosclerosis. Circ. Res. 61:(suppl. II):II-74-II-80.

8. Andrews, H. E., K. R. Bruckdorfer, R. C. Dunn, and M. Jacobs. 1987. Low-density lipoproteins inhibit endothelium-dependent relaxation in rabbit aorta. Nature (Lond.). 327:237-239.

9. Golino, P., P. R. Maroko, and T. E. Carew. 1987. The effect of acute 
hypercholesterolemia on myocardial infarct size and the no-reflow phenomenon during coronary occlusion-reperfusion. Circulation. 75:292-298.

10. Osborne, J. A., P. H., Lento, M. R. Siegfried, G. L. Stahl, B. Fusman, and A. M. Leder. 1989. Cardiovascular effects of acute hypercholesterolemia in rabbits. J. Clin. Invest. 83:465-473.

11. Hayashi, T., T. Ishikawa, M. Naito, M. Kuzuya, C. Funaki, K. Asai, H. Hidaka, and F. Kuzuya. 1991. Low level hyperlipidemia impairs endotheliumindependent relaxation of porcine coronary arteries by two mechanisms. Atherosclerosis. 87:23-38.

12. Kaplan, R., H. S. Aynedjian, D. Schlondorff, and N. Bank. 1990. Renal vasoconstriction caused by short-term cholesterol feeding is corrected by thromboxane antagonist or probucol. J. Clin. Invest. 86:1707-1714.

13. Forstermann, U., A. Mugge, U. Alheid, A. Haverich, and J. C. Frolich. 1988. Selective attenuation of endothelium-mediated vasodilation in atherosclerotic human coronary arteries. Circ. Res. 62:185-190.

14. Kugiyama, K., S. A. Kerns, J. D. Morrissett, R. Roberts, and P. D. Henry. 1990. Impairment of endothelium-dependent arterial relaxation by lysolecithin in modified low-density lipoproteins. Nature (Lond.). 344:160-162.

15. Simon, B. C., L. D. Cunningham, and R. A. Cohen. 1990. Oxidized low density lipoproteins cause contraction and inhibit endothelium-dependent relaxation in the pig coronary artery. J. Clin. Invest. 86:75-79.

16. Henriksen, T., S. A. Evensen, and B. Carlander. 1979. Injury to human endothelial cells in culture induced by low density lipoprotein. Scand. J. Clin. Lab. Invest. 39:361-368.

17. Hessler, J. R., A. L. Robertson, Jr., and G. M. Chisholm. 1979. LDL-induced cytotoxicity and its inhibition by HDL in human vascular and smooth muscle and endothelial cells in culture. Atherosclerosis. 32:213-229.

18. Steinbrecher, U. P., S. Parthasarathy, D. S. Leake, J. L. Witztum, and D. Steinberg. 1984. Modification of low density lipoprotein by endothelial cells involves lipid peroxidation and degradation of low density lipoprotein phospholipids. Proc. Natl. Acad. Sci. USA. 81:3883-3887.

19. Parthasarathy, S., U. P. Steinbrecher, J. Barnett, J. L. Witztum, and D. Steinberg. 1985. The essential role of phospholipase $A_{2}$ activity in endothelia cell-induced modification of low density lipoprotein. Proc. Natl. Acad. Sci. USA 82:3000-3004.

20. van Hinsbergh, V. W. M., M. Scheffer, L. Havekes, and H. J. M. Kempen. 1986. Role of endothelial cells and their products in the modification of low-density lipoproteins. Biochim. Biophys. Acta. 878:49-64.

21. Guerra, R., Jr., A. F. A. Brotherton, P. J. Goodwin, C. R. Clark, M. L. Armstrong, and D. G. Harrison. 1989. Mechanisms of abnormal endotheliumdependent vascular relaxation in atherosclerosis: implications for altered autocrine and paracrine functions of EDRF. Blood Vessels. 26:300-314.

22. Minor, R. L., P. R. Myers, R. Guerra, Jr., J. N. Bates, and D. G. Harrison. 1990. Diet-induced atherosclerosis increases the release of nitrogen oxides from rabbit aorta. J. Clin. Invest. 86:2109-2116.

23. Cooke, J. P., N. A. Andon, X. J. Girerd, A. T. Hirsch, and M. A. Creager. 1991. Arginine restores cholinergic relaxation of hypercholesterolemic rabbit thoracic aorta. Circulation. 83:1057-1062.

24. Rossitch, E., E. Alexander III, P. McL. Black, and J. P. Cooke. 1991.
L-arginine normalizes endothelial function in cerebral vessels from hypercholesterolemic rabbits. J. Clin. Invest. 87:1295-1299.

25. Girerd, X. J., A. T. Hirsch, J. P. Cooke, V. J. Dzau, and M. A. Creager. 1990. L-arginine augments endothelium-dependent vasodilation in cholesterolfed rabbits. Circ. Res. 67:1301-1308.

26. Bank, N., M. A. G. Lahorra, H. S. Aynedjian, and B. M. Wilkes. 1988. Sodium restriction corrects hyperfiltration of diabetes. Am. J. Physiol. 254(Renal, Fluid Electrolyte Physiol. 23):F668-F676.

27. Bank, N., P. Mower, H. S. Aynedjian, B. M. Wilkes, and S. Silverman. 1989. Sorbinil prevents glomerular hyperperfusion in diabetic rats. Am. J. Physiol. 256(Renal, Fluid, Electrolyte Physiol. 25):F1000-F1006.

28. Deen, W. M., C. R. Robertson, and B. M. Brenner. 1972. A model of glomerular ultrafiltration in the rat. Am. J. Physiol. 223:1178-1183.

29. Allain, C. A., L. S. Poon, C. S. G. Chan, W. Richmond, and P. C. Fu. 1974. Enzymatic determination of total serum cholesterol. Clin. Chem. 20:470475.

30. Bucolo, G., and H. David. 1973. Quantitative determination of serum triglycerides by the use of enzymes. Clin. Chem. 19:476-482.

31. Stuart, M. J., J. M. Gerrard, and J. G. White. 1980. Effect of cholesterol on production of thromboxane $\mathrm{B}_{2}$ by platelets in vitro. $N$. Engl. J. Med. 302:6-10.

32. Beitz, J., H.-U. Block, A. Beitz, G. Muller, L. Winkler, R. Dargel, and H.-J. Mest. 1986. Endogenous lipoproteins modify the thromboxane formation capacity of platelets. Atherosclerosis. 60:95-99.

33. Ardlie, N. G., M. L. Selley, and L. A. Simons. 1989. Platelet activation by oxidatively modified low density lipoprotein. Atherosclerosis. 76:127-134.

34. Luscher, T. F., and P. M. Vanhoutte. 1986. Endothelium-dependent contractions to acetylcholine in the aorta of the spontaneously hypertensive rat. Hypertension. 8:344-348.

35. Tesfamariam, B., M. L. Brown, D. Deykin, and R. A. Cohen. 1990. Elevated glucose promotes generation of endothelium-derived vasoconstrictor prostanoids in rabbit aorta. J. Clin. Invest. 85:929-932.

36. Pagano, P. J., L. Lin, W. C. Sessa, and A. Nasjletti. 1991. Arachidonic acid elicits endothelium-dependent release from the rabbit aorta of a constrictor prostanoid resembling prostaglandin endoperoxides. Circ. Res. 69:396-405.

37. Neugarten, J., and D. Schlondorff. 1991. Lipoprotein interactions with glomerular cells and matrix. In Contemporary Issues in Nephrology. W. F. Keane and J. H. Stein, editors. Churchill Livingstone, New York. 173-206.

38. Kasiske, B. L., M. P. O'Donnell, P. G. Schmitz, Y. Kim, and W. F. Keane. 1990. Renal injury of diet-induced hypercholesterolemia in rats. Kidney Int. 37:880-891.

39. Keane, W. F., W. S. M. Mulcahy, B. L. Kasiske, Y. Kim, and M. P. O'Donnell. 1991. Hyperlipidemia and progressive renal disease. Kidney Int. 39(Suppl.):S-41-S-48.

40. Mene, P., H. E. Abboud, and M. J. Dunn. 1990. Regulation of human mesangial cell growth in culture by thromboxane $\mathrm{A}_{2}$ and prostacyclin. Kidney Int. 38:232-239.

41. Klotman, P., L. Bruggeman, J. Hassell, E. Horigan, G. Martin, and Y. Yamada. 1989. Regulation of extracellular matrix by thromboxane. Kidney Int. 35:294. (Abstr.) 